\title{
Histopathological Spectrum of Nephrectomy Specimen in a tertiary Care Centre: With an Emphasis on Chronic Pyelonephritis
}

\author{
Shanmugasamy. K*, Anandrajvaithy, Venkatraman. K and Dhananjay S kotasthane
}

Department of pathology Mahathma Gandhi Medical College and Research Institute, SBV university Pillaiyarkuppam, Pondicherry, India

\begin{abstract}
Introduction: Nephrectomy is a common procedure in urological practice done for various conditions like calculi, chronic pyelonephritis, malignancy, obstruction, injury, etc with wide range of morbidity and mortality. In our country there is increased in number of end stage renal disease treated with dialysis and transplantation. So it is mandatory to study the spectrum of renal disease with special emphasis on Chronic pyelonephritis.

Methods: This study was carried out in the Department of Pathology, Mahatma Gandhi Medical College and Research Institute, Sri Balaji Vidhyapeeth University, Pondicherry. All the nephrectomy specimen received in the department over a period of three years (January, 2013 to December 2015) were included. A total of 34 cases of nephrectomy specimen were studied during this period.

Results: Out of 34 cases of nephrectomy, 24 were done for inflammatory lesions, 8 cases for tumor and 2 cases shows cystic lesion. Out of 24 cases of pyelonephritis, 6 cases were associated with nephrolithiasis. Out of 8 tumor cases, 6 cases were Renal cell carcinoma.

Conclusion: To conclude, Nephrectomies is mostly done for non-neoplastic lesion. CPN also seems to be associated with various findings like pyonephrosis, calculi, malignancies etc. Hence it is mandatory to study each CPN case in detail along with clinical and radiological findings.
\end{abstract}

Keywords: Nephrectomy, Renal Cell Carcinoma, Chronic Pyelonephritis

\section{Introduction}

Kidneys are vital organs of the body with multiple functions like excretory function, acid base balance and maintenance of salt and water metabolism. Simple nephrectomy is a common procedure in urological practice and it is indicated in patients with an irreversible damaged kidney resulting from symptomatic chronic infections, obstruction, calculus, severe traumatic injury and renal dysplasia ${ }^{[1]}$.Kidney can be affected by various pathological conditions like cystic disease, glomerulonephritis, pyelonephritis, renovascular hypertension, obstruction, calculous disease, benign and malignant tumor, etc some of which may requires surgical treatment and some may requires medical treatment ${ }^{[2]}$.

Chronic pyelonephritis with hydronephrosis is the most common type of nephrectomy specimen for non-neoplastic conditions due to increase in the incidence of pelviureteric junction obstruction by upper ureteric calculi, whereas in the neoplastic group, renal cell carcinoma is the most common due to increase in the incidence in chronic smokers ${ }^{[3]}$. Most of the patients with chronic pyelonephritis leads to permanent and progressive damage to the renal parenchyma ending up with Non-functioning kidney.
Most of the patients reach hospital with either obstructive symptoms or with acute on chronic renal failure. In our country there is increased in number of end stage renal disease treated with dialysis and transplantation. So it is mandatory to study the spectrum of renal disease with special emphasis on Chronic pyelonephritis.Radical or Partial nephrectomy is the treatment of choice for a greater proportion of patients with renal tumors ${ }^{[4]}$.

The aim of this article was to study the histopathological spectrum of nephrecteomy specimen with an emphasis on pyelonephritis.

\section{Materials and Methods}

This study was carried out in the Department of Pathology, Mahatma Gandhi Medical College and Research Institute, Sri Balaji Vidhyapeeth University, Pondicherry. All the nephrectomy specimen received in the department over a period of three years (January, 2013 to December 2015) were included. A total of 34 cases of nephrectomy specimen were studied during this period.Patients details were noted, which includes age, sex, clinical findings and radiological investigations. This is a retrospective study, so all nephrectomy cases were taken out from the records 
and slides were reviewed. All these specimens were fixed in $10 \%$ buffered formalin, then processed into paraffin embedded sections \& stained with haematoxylin \& eosin.

\section{Results}

The present study includes 34 nephrectomy cases analyzed during the period of January 2013 to December 2015. Among 34 nephrectomy cases, higher incidence were observed in fifth and sixth decades of life with equal preponderance of male and female as shown in [Table 1] and [Table 2].

Loin pain (28 cases) was the most common clinical presenting complaints noted, followed by burning micturition, fever and hematuria. 5 cases presented with abdominal lump and four cases presented with oliguria as shown in [Table 3].

From these 34 nephrectomy cases, $75 \%$ of the cases were non-neoplastic lesions and $25 \%$ of the cases were neoplastic lesions as shown in [Table 4]. In the histopathological spectrum of nephrectomy specimen with 34 nephrectomy cases, maximum number ( 24 cases) of cases were found to be chronic pyelonephritis (CPN). Out of this 24 CPN cases, maximum number of cases were found to be associated with pyonephrosis (PN) and Nephrolithiasis as shown in [Table 5]. Granuloma s/o Tuberculosis, Mycormycosis and Hydatid cyst covers minimum number of cases each. Out of 34 cases 6 cases of renal cell carcinoma, 1 case of oncocytoma and 1 case of angiomyolipoma were documented.

In Gross findings in pyelonephritis, predominant number of cases was found to have loss of cortico medullary junction with $91.7 \%$ and Dilatation of pelvi-calyceal system with $95.8 \%$. Also $41.7 \%$ of cases were found to be cortical scarring and $25 \%$ of cases have calculi as shown in [Fig 1].

In microscopic findings of nephrectomy cases, Tubular atrophy and Thyroidisation of tubules were seen in 21 cases each. Maximum number of cases i.e. 22 cases $(91.7 \%)$ were found to be interstitial fibrosis as shown in [Table 6]. Glomerular sclerosis with hyalinization and periglomerular fibrosis were seen in $62.5 \%$ and $66.7 \%$ respectively.

In this spectrum, benign tumor accounted for two cases and malignant tumor accounted for 6 cases and Renal cell carcinoma-clear cell type is the most common malignant tumor seen in this study as shown in [Table 7].

Table 1: Distribution of nephrectomy specimens according to age.

\begin{tabular}{|c|c|c|}
\hline Age & Number of Cases & Percentage \\
\hline $0-20$ & 1 & $9 \%$ \\
\hline $21-30$ & 3 & $9 \%$ \\
\hline $31-40$ & 3 & $20.5 \%$ \\
\hline $41-50$ & 7 & $29.5 \%$ \\
\hline $51-60$ & 10 & $26 \%$ \\
\hline $61-70$ & 9 & $3 \%$ \\
\hline $71-80$ & 1 & $100 \%$ \\
\hline Total & 34 & 2 \\
\hline
\end{tabular}

Table 2: Distribution of nephrectomyspecimens according to gender

\begin{tabular}{|l|c|c|c|}
\hline Type of lesion & Male & Female & Total \\
\hline Non -neoplastic & 14 & 12 & 26 \\
\hline Neoplastic & 3 & 5 & 8 \\
\hline Total & 17 & 17 & 34 \\
\hline
\end{tabular}

Table 3: Clinical presentation.

\begin{tabular}{|c|c|c|}
\hline S.No & Symptoms & Number of cases \\
\hline 1 & Abdomen lump & 28 \\
\hline 2 & Flank pain & 20 \\
\hline 3 & Hematuria & 26 \\
\hline 4 & Burning micturition & 22 \\
\hline 5 & Fever & 4 \\
\hline
\end{tabular}


Table 4: Spectrum of histopathological diagnosis in nephrectomy specimen.

\begin{tabular}{|l|c|c|}
\hline Lesion & Number of Cases & Percentage \\
\hline Cystic lesion & 2 & $6 \%$ \\
\hline Chronic pyelonephritis & 24 & $70.5 \%$ \\
\hline Benign & 2 & $6.0 \%$ \\
\hline Renal cell carcinoma & 6 & $17.5 \%$ \\
\hline Total & $\mathbf{3 4}$ & $\mathbf{1 0 0 \%}$ \\
\hline
\end{tabular}

Table 5: Chronic pyelonephritis (CPN) with associated findings.

\begin{tabular}{|c|l|c|c|}
\hline S.No & Associated findings & Number of Cases & Percentage \\
\hline 1. & CPN & 5 & $21 \%$ \\
\hline 2. & Acute on chronic CPN & 3 & $12.5 \%$ \\
\hline 3. & CPN with PN and nephrolithiasis & 6 & $25 \%$ \\
\hline 4. & CPN with xantho-granulomatous change & 5 & $21 \%$ \\
\hline 5. & CPN with lipomatous change & 1 & $4 \%$ \\
\hline 6. & CPN with granuloma s/o Tuberculosis & 2 & $8.5 \%$ \\
\hline 7. & CPN with Mucormycosis & 1 & $4 \%$ \\
\hline 8. & CPN with Hydatid cyst & 1 & $\mathbf{2 4}$ \\
\hline & Total & $\mathbf{2 4}$ & $\mathbf{1 0 0 \%}$ \\
\hline
\end{tabular}

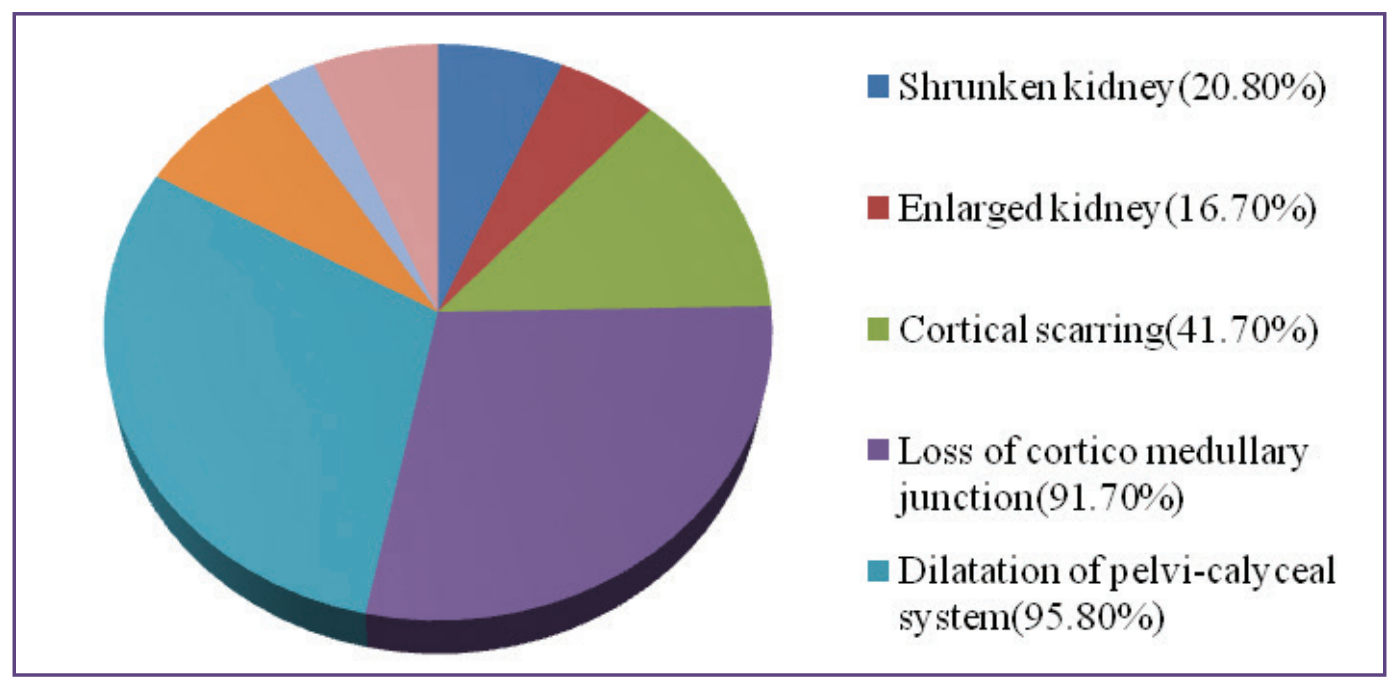

Graph 1: Gross findings.

Table 6: Microscopic findings in Pyelonephritis.

\begin{tabular}{|c|c|c|}
\hline Microscopic findings & Number of cases & Percentage \\
\hline Glomerular sclerosis with hyalinization & 15 & $62.5 \%$ \\
\hline Periglomerular fibrosis & 16 & $66.7 \%$ \\
\hline Tubular atrophy & 21 & $87.5 \%$ \\
\hline Thyroidisation of tubules & 21 & $87.5 \%$ \\
\hline $\begin{array}{l}\text { Interstitial inflammation } \\
\text { Acute } \\
\text { Chronic } \\
\text { Granulomas } \\
\text { Foamy macrophages }\end{array}$ & $\begin{array}{c}2 \\
16 \\
3 \\
1\end{array}$ & $\begin{array}{c}8.3 \% \\
66.7 \% \\
12.5 \% \\
4.2 \%\end{array}$ \\
\hline Interstitial fibrosis & 22 & $91.7 \%$ \\
\hline Intimal sclerosis of arcuate vessels & 15 & $62.5 \%$ \\
\hline
\end{tabular}




\begin{tabular}{|l|c|c|}
\hline Microscopic findings & Number of cases & Percentage \\
\hline Hyaline Arteriosclerosis & 14 & $58.3 \%$ \\
\hline
\end{tabular}

Table 7: Distribution of tumors.

\begin{tabular}{|l|c|c|}
\hline Tumors & Number of cases & Percentage \\
\hline Angiomyolipoma & 1 & $12.5 \%$ \\
\hline Renal Oncocytoma & 1 & $12.5 \%$ \\
\hline RCC- Clear cell type & 5 & $62.5 \%$ \\
\hline RCC- Papillary type & 1 & $12.5 \%$ \\
\hline TOTAL & $\mathbf{8}$ & $\mathbf{1 0 0 \%}$ \\
\hline
\end{tabular}

Table 8: Furhman nuclear grading of Renal cell carcinoma.

\begin{tabular}{|c|c|c|c|}
\hline S.No & Furhman nuclear grade & Number of cases & Percentage \\
\hline 1 & Grade I & 1 & $16.5 \%$ \\
\hline 2 & Grade II & 4 & $67 \%$ \\
\hline 3 & Grade III & 1 & $16.5 \%$ \\
\hline 4 & Grade IV & - & - \\
\hline
\end{tabular}

\section{Discussion}

In our study, 34 nephrectomy cases were analyzed. Out of 34 nephrectomy cases 26 cases were non-neoplastic and 8 cases were neoplastic. Similar findings were observed by AifaAimanet $\mathrm{al}^{[3]}$ and Shaila et al ${ }^{[8]}$

In the present study majority of nephrectomy were done in sixth decade $(29.5 \%)$ followed by seventh decade(26\%). However it is variable with study of Muhammad et al ${ }^{[9]}$, who observed in third decade $(30 \%)$ followed by fourth decade(20\%).Among the nephrectomy cases 17 cases were male and 17 case were female. This finding is variable to study done by Divyashreeet $\mathrm{al}^{[6]}$ and Nusrat et $\mathrm{al}^{[7]}$.

In our study majority of the cases presented with loin pain (28 cases) followed by urinary symptoms like burning micturition, hematuria and fever. A majority of patients who presented with hematuria had malignant lesions. These findings are in concordance with study conducted by A. Aiman ${ }^{[3]}$ and Popat et a ${ }^{[10]}$.

In our study the most common lesion observed was chronic pyelonephritis(70.5\%), which is followed by Renal cell carcinoma as studied by Popat et $\mathrm{al}^{[10]}$.

Radiologically cystic lesions and calculi are identified. Among five cases of Xanthogranulomatous pyelonephritis, all five cases radiologically showed calculi. Out of two cases of tuberculosis one showed calculi, which was in discordance with study conducted by A. Aiman et al ${ }^{[3]}$.

On critical evaluation majority of the chronic pyelonephritis cases calculi. It is due to various factors like dietary, genetic and sedentary life styles. Commonly patient develops calcium oxalate stones which occurs due to consumption of hard water, supersaturation of calcium oxalate and lower urinary citrate concentration ${ }^{[14][15]}$.
Most of the renal stones tends to recur, which also depends upon stone type. Decreased supersaturation of the urinary filtrate and increased urinary citrate concentration will reduce the incidence of stone recurrence ${ }^{[15,16]}$. Apart from renal calculi other risk factors for chronic pyelonephritis are vesico-ureteral reflux, benign prostatic hyperplasia and urinary tract infection in pregnancy.

In the present study, two cystic lesions are documented, one case is simple renal cyst and another case is cystic renal dysplasia which is similar to the study conducted by Divyashree et $\mathrm{al}^{[6]}$. Among 24 cases of chronic pyelonephritis(CPN), grossly majority of cases shows dilatation of pelvi-calyceal system( 23 cases) and loss of cortico-medullary junction(22 cases), which is concordance with study conducted by Datta et al[11].

Out of 24 cases of CPN [Figure-1], microscopically 6 cases were diagnosed to CPN with nephrolithiasis five cases with Xanthogranulomatous pyelonephritis and 2 cases shows tubercular changes and other associated findings include pyonephrosis, lipomatous change, mucormycosis and hydatid cyst as similar to study done by Shikhaet $\mathrm{al}^{[5]}$. Globally the incidence of xanthogranulomatous pyelonephritis is 0.6 to $1 \%$ with female preponderance ${ }^{[13]}$, but in our study 5 cases have been reported which is found to be discordance with the other study.

In the present study nephrectomy done for 8 tumor cases, out of which 6 cases are renal cell carcinoma [Figure-2], 1 case is angiomyolipoma and 1 case is oncocytoma [Figure-3] which is in concordance with study conducted by EI Malick EM et al ${ }^{[12]}$.

\section{Conclusion}

Our study reveals that nephrectomies were done most commonly for non-neoplastic lesions when compared to 


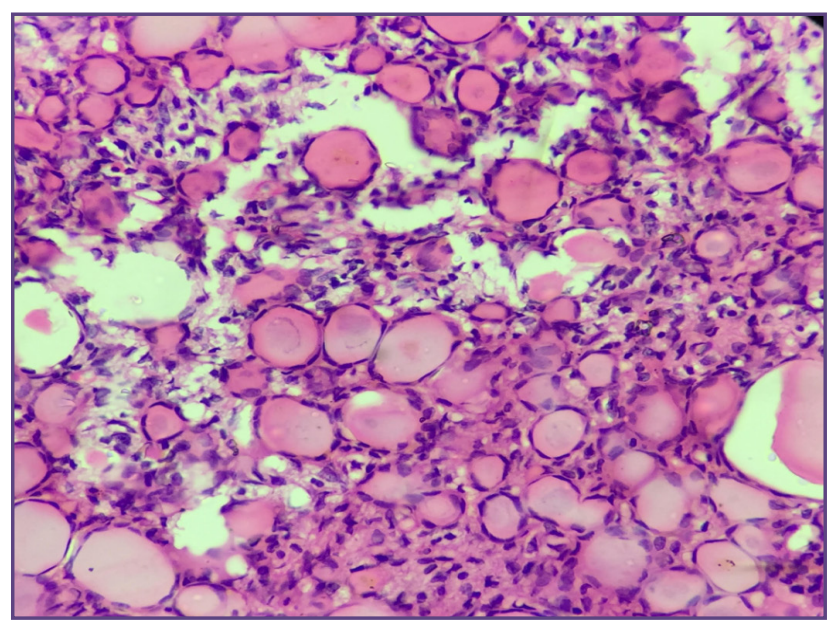

FIG. 1: Chronic Pyelonephritis. Microphotograph showing thyroidisation of tubules. (H\&E, 10X)

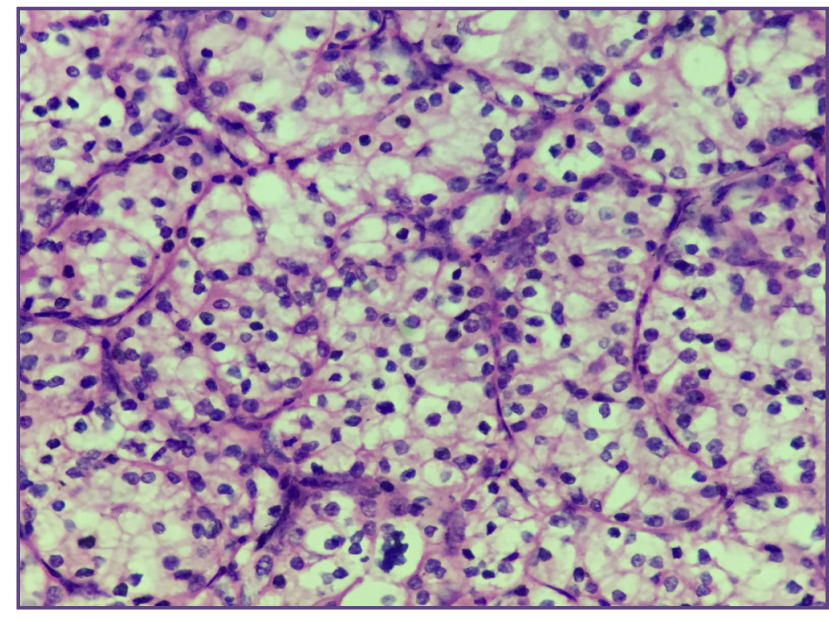

Fig. 2: Renal Cell Carcinoma-Clear Cell Type. Microphotograph showing clear cells with prominent delicate vasculature. (H\&E, $40 \mathrm{X}$ )

neoplastic lesions. Renal cell carcinoma- Clear cell type is the most common malignant tumor. Chronic pyelonephritis (CPN) is the most common non-neoplastic lesion with series of microscopic changes like thyroidisation of tubules, tubular atrophy, interstitial fibrosis, etc. CPN also seems to be associated with various findings like pyonephrosis, calculi, malignancies etc. Hence it is mandatory to study each CPN case in detail along with clinical and radiological findings.

\section{References}

1. Monalisa Hui et al. Histopathological spectrum of pediatric nephrectomies. Indian Journal of Pathology and Microbiology, 2010; 53(1):101-102.

2. Kumar MU, Yelikar BR, Patil G, Karigoudar MH, Pande P, Patil SB. Spectrum of histopathological lesions in Nephrectomy specimens- A two year study in a tertiary care

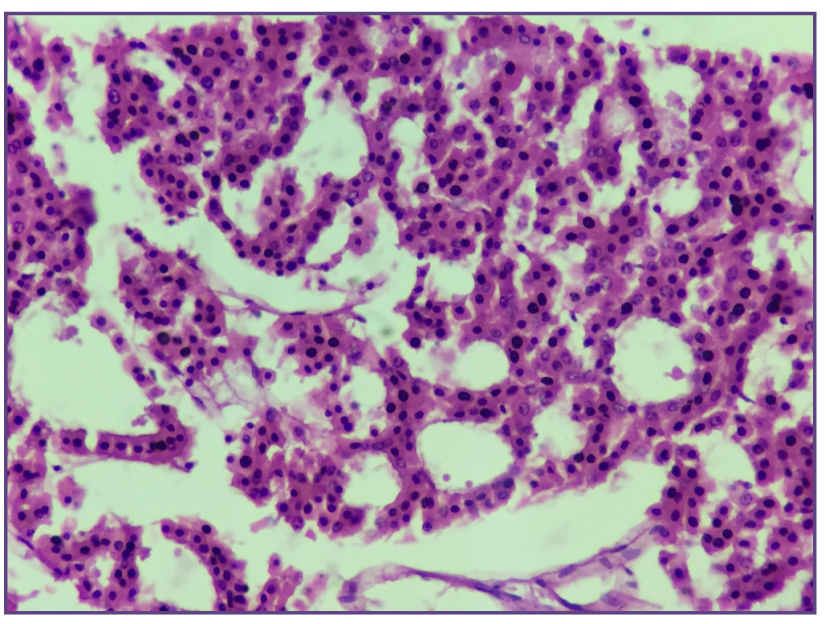

Fig. 3: Renal Oncocytoma- Microphotographs showing oncocytes. (H\&E, 10X).

hospital. International Journal of Research in Pharmaceutical and Biomedical Sciences. 2012; 3:1787-89.

3. Aiman A, Singh K, Yasir M. Histopathological spectrum of lesions in nephrectomy specimens: A five-year experience in a tertiary care hospital. J SciSoc 2013;40:148-54.

4. Murphy WM, Grignon DJ, Perlman EJ. Kidney tumours in adults. In: Silverberg SG, editor. Tumours of the Kidney, Bladder and Related Urinary Structures - AFIP Atlas of TumorPatholog. Series 4, chapt. 2. Washington DC; AFIP; 2004. p. 101-240.

5. Gairangbam S, Konjengbam R. Histopathological spectrum of non-neoplastic \& neoplastic lesions in nephrectomy specimens. J. Evid. Based Med. Healthcare. 2016;3(16):627-29

6. Divyashree B. Venkatesh NK, Madhusudhan HR, Hanumantha, Raju BK. Pathological spectrum of nonneoplastic diseases in the Nephrectomy specimens. J of Evidence Based Med \& Hlthcare. 2014;1(15):1909-20. 
7. Bashir N, Bashir Y, Shah P, et al. Histopathological study of renal tumors in resected Nephrectomy specimens - An experience from teritary care centre. National Journal of Medical Research. 2015;5(1):25-29.

8. Shaila, Nityananda BS, Arasi T. Spectrum of lesions in Nephrectomy specimens in tertiary care hospital. J of Evolution of Med and Dent Sci. 2015;4(73):12714-25.

9. Muhammad A, Khan K, Rana S. Nephrectomy- an overview, Pak J Surj,2012, 28(2):102-105.

10. Popat VC, Kumar MP, Udani D, Mundra MP, Vora DN, Porecha MM. A study on culprit factors ultimately demanding nephrectomy. Internet J Urol 2010;7.

11. Datta B, Moitra T, Chaudhury D N, Halder B. Analysis of 88 nephrectomies in a rural tertiary care centre of India. Saudi J Kid Dis Transpl. 2012;23(2):409-413.
12. El Malik EM, Memon SR, Ibrahim AL, Al Gizawi A, Ghali AM. Nephrectomy in Adults: Asir Hospital Experience. Saudi J Kidney Dis Transpl 1997;8:423-7.

13. Siddappa S, Ramprasad K, Muddegowda MK. Xanthogranulomatous pyelonephritis: A retrospective review of 16 cases. Korean J Urol. 2011;52:421-424.

14. Suryawanshi KH, Damle RP, Dravid NV, Rawandale AP, Surana A. Histomorphological Analysis of Lesions In Nephrectomy Specimens: A 4 Years Study In A Rural Hospital In India-Our Experience. Annals of Pathology and Laboratory Medicine, 2017; 4:3.

15. Han H, Segal AM, Seifter JL, Dwyer JT. Nutritional Management of Kidney Stones (Nephrolithiasis). ClinNutr Res 2015;4 :137-152.

16. Saxena A, Sharma RK. Nutritional aspect of nephrolithiasis. Indian J Urol. 2010 Oct-Dec; 26(4): 523-530.

*Corresponding author:

Dr. Shanmugasamy. K, Department of pathology, Mahathma Gandhi Medical College and Research Institute, SBV university,

Pillaiyarkuppam, Pondicherry-India 607402.

Phone: +91 9487920242

Email: samypatho@gmail.com

Date of Submission : 15.06.2017

Date of Acceptance : 07.07.2017

Financial or other Competing Interests: None.
Date of Publication : 30.10.2017 